\title{
Publicações Recebidas
}

\section{Revistas}

Apogeo, n. $\stackrel{\circ}{34 / 08}$

Lisboa: Associação de Professores de Geografia

Caderno Brasileiro de Ensino de Física, n.ำ 02/08

Brasil: Universidade Federal de Santa Catarina

Educação e Filosofia, n. 9 42/07

Brasil: Universidade Federal de Uberlândia

Estudos em Avaliação Educacional, n. $.039 / 08$

Brasil: Fundação Carlos Chagas

Historia Agrária, n. ${ }^{\circ}$ 45/08

Espanha: Universidad de Murcia y la Universitat Autònoma de Barcelona

Humanística e Teologia, $.^{\circ} 01 / 08$

Porto: Faculdade de Teologia

Noesis, n. $074 / 08$

Lisboa: Direcção-Geral de Inovação e de Desenvolvimento Curricular

Papeles Salmantinos de Educación, n.ำ 10/08

Espanha: Facultad de Ciencias de la Educación - Universidad Pontificia de Salamanca

Revista Crítica de Ciências Sociais, n. $.91 / 08$

Coimbra: Centro de Estudos Sociais

Revista de Educación, n.ํㅜ 347/08

Espanha: Ministerio de Educación, Política Social y Deporte - Instituto de Evaluación

Sociologia, Problemas e Práticas, n. ${ }^{\circ}$ 55/07

Lisboa: Centro de Investigação e Estudos de Sociologia - Instituto Superior de Ciências do Trabalho e da Empresa

Trabalho, Educação e Saúde, n.ำs 1 e 2/03, n.ํs 1 e 2/04, n.ํs 1 e 2/05, n.ำs 1 e 2/06, n. -1 , 2 e 3/07-08 e n. $.1 / 08$

Brasil: Fundação Oswaldo Cruz - Escola Politécnica de Saúde Joaquim Venâncio 
$240 \mid$ Publicações recebidas

\section{Monografias}

ALVES, Natália (2008). Juventudes e Inserção Profissional. Lisboa: Educa, Unidade de I\&D de Ciências da Educação. 